Etnográfica

Revista do Centro em Rede de Investigação em

Antropologia

vol. 25 (1) | 2021

Vol. $25(1)$

\title{
Entre as práticas cinematográficas e as práticas turísticas: um olhar etnográfico sobre a produção de filmes turísticos portugueses na década de 1960
}

Between filmmaking practices and tourist practices: an ethnographic look on the production of Portuguese tourism films in the 1960s

\section{Sofia Sampaio}

\section{(2) OpenEdition}

\section{Journals}

\section{Edição electrónica}

URL: https://journals.openedition.org/etnografica/9976

DOI: 10.4000/etnografica.9976

ISSN: 2182-2891

\section{Editora}

Centro em Rede de Investigação em Antropologia

Edição impressa

Paginação: 193-210

ISSN: 0873-6561

\section{Refêrencia eletrónica}

Sofia Sampaio, «Entre as práticas cinematográficas e as práticas turísticas: um olhar etnográfico sobre a produção de filmes turísticos portugueses na década de 1960», Etnográfica [Online], vol. 25 (1) | 2021, posto online no dia 05 março 2021, consultado o 30 janeiro 2022. URL: http:// journals.openedition.org/etnografica/9976 ; DOI: https://doi.org/10.4000/etnografica.9976

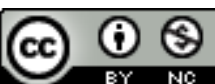

Etnográfica is licensed under a Creative Commons Attribution-NonCommercial 4.0 International License. 


\section{Entre as práticas cinematográficas e as práticas turísticas: um olhar etnográfico sobre a produção de filmes turísticos portugueses na década de 1960}

\section{Sofia Sampaio}

O artigo explora a relação entre práticas cinematográficas e práticas turísticas na produção de filmes turísticos portugueses da década de 1960. Para além da análise de imagens depositadas no Arquivo Nacional das Imagens em Movimento (ANIM) da Cinemateca Portuguesa-Museu do Cinema, recorro ao testemunho de profissionais do cinema e seus familiares para tentar recuperar os contextos e as práticas de produção destes filmes, numa espécie de etnografia retrospectiva do campo de produção cinematográfica desse tempo. Ainda que frequentemente relegados (pelos próprios realizadores) para uma posição secundária ou marginal, estes e outros filmes de utilidade desempenharam um papel importante na carreira destes profissionais, permitindo-lhes desenvolver uma práxis profissional reconhecida dentro e fora do meio cinematográfico e, em geral, permanecer dentro de uma profissão marcada por uma elevada precariedade laboral. Na linha de teorias "não-representacionais" ou "mais-do-que-representacionais", analiso a produção de imagens em movimento turísticas à luz da sobreposição de experiências cinematográficas e turísticas incarnadas e situadas, e não tanto da imposição directa de um "olhar turístico" por parte quer da indústria quer do Estado.

PALAVRAS-CHAVE: filmes turísticos, práticas, Portugal (anos 60), arquivo de imagens em movimento, etnografia retrospectiva.

Between filmmaking practices and tourist practices: an ethnographic look on the production of Portuguese tourism films in the 1960s - This article explores the relationship between filmmaking practices and tourist practices in the production of Portuguese tourism films in the 1960s. Besides analysing the images deposited in the National Archive of the Moving Images (ANIM) of the Portuguese Film Museum (Cinemateca Portuguesa-Museu do Cinema), I draw on interviews with filmmakers and their relatives to retrieve the production contexts and practices of the films, in a kind of retrospective ethnography of the film production field of those times. Frequently relegated (by the filmmakers themselves) to a secondary or marginal position, these and other utility films played an important part in the careers of these professionals, allowing them to develop a professional praxis recognised inside and outside the field and, in general, remain in a profession shaped by great instability. In line with "non-representational" or "more-than-representational" theories, I analyse the production of tourism moving images in the light of embodied and situated filmmaking and tourist experi- 
ences that overlap and not so much of the direct imposition of a "tourist gaze" by the industry or the State.

KEYWORDS: tourism films, practices, Portugal (1960s), moving image archives, retrospective ethnography.

SAMPAIO, Sofia (sofia.sampaio@ics.ulisboa.pt) - Instituto de Ciências Sociais, Universidade de Lisboa, Portugal.

OS DESENVOLVIMENTOS TEÓRICOS MAIS RECENTES SOBRE TURISMO têm procurado recuperar dimensões corporais e sensoriais que estiveram ausentes ou permaneciam marginais em grande parte dos estudos (Obrador 2008). ${ }^{1}$ A ênfase recai agora no fazer - no fazer turismo - daí a importância que conceitos como "performance", "corporalidade", "imersão" e "prática" têm vindo a adquirir na literatura (Veijola e Jokinen 1994; Edensor 2000; Coleman e Crang 2002; Crouch e Desforges 2003; Obrador 2003). Sob o impulso de teorias "não-representacionais" (Thrift 2007) ou "mais-do-que-representacionais" (Lorimer 2005), as materialidades do turismo, estudadas em processo (Crouch 2002), têm vindo a assumir um maior relevo, complementando ou ultrapassando as abordagens puramente semióticas e discursivas que dominavam esta área de conhecimento (Haldrup e Larsen 2006; Sampaio 2013). A reflexão que tenho vindo a realizar sobre as intersecções entre o turístico e o visual - tendo como base um corpus de imagens em movimento realizadas em Portugal ao longo do século $\mathrm{XX}^{2}$ - partilha e beneficia de algumas destas tendências teóricas. $\mathrm{O}$ visionamento em série de imagens de arquivo de várias épocas alertou-me para o que havia de parecido e de diferente nessas imagens, mas também me encorajou a desviar a atenção da questão das representações

l Este trabalho resulta de investigação enquadrada no programa Investigador FCT (IF/003 13/2013) e desenvolvida entre Janeiro de 2014 e Dezembro de 2018, no Centro em Rede de Investigação em Antropologia (CRIA). Versões preliminares foram apresentadas ao colóquio "Modos de fazer, modos de ser: práticas artísticas na e com a antropologia” e ao 2. ${ }^{\circ}$ Encontro do Grupo de Investigação Práticas e Políticas da Cultura do CRIA, que decorreram, respectivamente, em Março e Outubro de 2017, no CRIA (UID/ANT/04038/2013). Agradeço ao Nuno Domingos, que discutiu a minha comunicação, como debatedor, no segundo evento. Agradeço também, com especial apreço, aos profissionais de cinema entrevistados, bem como ao Gonçalo Mota e ao Sérgio Bordalo e Sá, que participaram na preparação e condução das entrevistas filmadas. O artigo segue a grafia anterior ao acordo ortográfico (AO90).

2 O corpus em causa é composto por imagens em movimento analógicas de não-ficção, em vários formatos, que fazem parte do acervo do Arquivo Nacional das Imagens em Movimento (ANIM) da Cinemateca Portuguesa-Museu do Cinema. Foi elaborado no âmbito do projecto exploratório "Atrás da Câmara: Práticas de Visualidade e Mobilidade no Filme Turístico Português" (EXPL/IVC-ANT/1706/2013), financiado pela FCT, acolhido pelo CRIA, e implementado entre Abril de 2014 e Setembro de 2015. 
para a questão das práticas. Ou seja, em vez de ver nessas iteracções a prova da resiliência de ideologias que, noutras épocas e regimes políticos, terão instrumentalizado o turismo e as suas representações, procurei indagar sobre aquilo que poderia dever-se às práticas turísticas e cinematográficas que estiveram na raiz dessas imagens. Por outras palavras, como hipótese de trabalho assumi que as imagens que me chegavam através do arquivo carregariam em si marcas, não apenas de uma ideologia dominante, mas também da convergência que tivera lugar, durante a produção destas imagens, destes dois tipos de práticas.

Esta hipótese originava-se num pressuposto teórico e acarretava implicações metodológicas. O pressuposto teórico era a insatisfação com o conceito de olhar turístico, proposto e vulgarizado pelo sociólogo britânico John Urry (2002 [1990]), que tem exercido grande influência sobre o estudo da visualidade turística. Ainda que submetido a reapreciações (Urry 2002 [1990]: 145-156; Urry e Larsen 2011), o carácter tendencialmente determinista (MacCannell 2001), estático e abstracto do olhar turístico (devedor do conceito de "olhar clínico" de Foucault, teoricamente estimulante, mas tendencialmente escopofóbico) tem dificultado o aparecimento de análises mais finas e matizadas da visualidade em contextos turísticos concretos. Na verdade, se o conceito de olhar turístico constitui um obstáculo à análise de imagens concretas, impedindo-nos de ver como se vê, ele é ainda menos útil quando se trata de analisar imagens em movimento, em relação às quais a teoria de Urry é, em larga medida, omissa (Sampaio 2015, 2020).

Estudos na área da fotografia têm desafiado as implicações determinísticas do olhar turístico, ao salientarem a qualidade performativa da fotografia turística amadora, uma prática que resulta tanto da citação de modelos preexistentes ("quotation") como da produção coreografada de novos planos ("framing"), o que faz com que estas fotografias tenham que ser entendidas como performadas para além de pré-formadas (Larsen 2005, 2006). Esta proposta é facilmente aplicável aos filmes amadores feitos por turistas, que resultam de práticas incarnadas e vividas em primeira mão, ${ }^{3}$ o que lhes valeu já a designação de "filmes de possessão" (Mota 2017: 98). A grande dúvida é saber se pode ser igualmente aplicada a filmes de promoção turística. À primeira vista, um filme de viagem feito por um turista denota uma experiência mais pessoal, directa e performativa do que um filme de promoção turística. Por outro lado, porquê assumir que os cineastas profissionais são praticantes menos incarnados do que os turistas que fazem filmes amadores? Não poderão essas outras práticas ser tão incarnadas e tão definidoras das imagens quanto o são as práticas dos cineastas amadores?

3 O termo "incarnado" é a minha opção de tradução para embodied, por me parecer menos ambíguo do que a alternativa "incorporado", habitualmente usado no sentido de "misturado", "admitido como membro" ou "incluído". 
A principal consequência metodológica desta hipótese de trabalho consistiu na realização de entrevistas semiestruturadas a profissionais do cinema que tinham estado envolvidos, durante a década de 60, na produção de algumas das imagens turísticas visionadas. A partir do cruzamento das imagens do arquivo e dos depoimentos recolhidos, tentei desenvolver uma espécie de "etnografia retrospectiva" ou "por recuo" (Almeida 2007, 2009: 46; Ferreira e Almeida 2017) ${ }^{4}$ do campo cinematográfico português desse tempo, com o objectivo de recuperar, na medida do possível, as práticas e os contextos de produção das imagens visionadas. ${ }^{5}$ Assim, entre Novembro de 2014 e Maio de 2015, entrevistámos cinco realizadores, um familiar de um realizador, um operador de câmara, um director de fotografia e um músico (na qualidade de compositor de música para cinema). Mais recentemente, entrevistei um sexto realizador. ${ }^{6}$

Os anos 60 são conhecidos, na história do cinema português, como um período excepcional, que viu o surgimento e a consolidação de apoios à produção de filmes e à formação de técnicos no estrangeiro por parte do Estado e de privados $;^{7}$ o reforço da participação em circuitos internacionais (sobretudo ao nível da co-produção e da exibição em festivais); e, em geral, o desenvolvimento de um clima propício à experimentação artística, que culminou na produção de um tipo de cinema que se passou a apresentar e a ser visto como "novo" (cf. Cunha 2018). O aparecimento e a expansão de actividades afins, tais como a televisão (a partir de 1957) e a publicidade, também desempenharam um papel de relevo nestas transformações. Todos os profissionais que entrevistei (excepto dois casos, que pertenciam a gerações mais antigas) estavam a dar os primeiros passos neste meio.

4 No trabalho destas autoras, o objecto de estudo é o próprio processo de rememoração, o forjamento da memória (individual e colectiva) e a articulação entre o público e o privado, a grande e a pequena história. Apesar de terem assomado na investigação, estas questões não constituíram uma preocupação central, pelo que não serão abordadas neste artigo.

5 A proposta de "desenterrar" práticas a partir de representações (os filmes) e discursos (as entrevistas) decorre da impossibilidade da observação directa e presencial. O que se recupera são sempre indícios, daí o veio conjectural que atravessa a minha análise.

6 O uso da primeira pessoa do plural, em partes deste artigo, não é majestático: as primeiras 12 entrevistas foram preparadas, conduzidas e filmadas com o apoio de dois bolseiros de investigação. Ainda que a intenção fosse entrevistar um leque abrangente de profissionais, as entrevistas acabaram por incidir sobre realizadores. A duração de cada entrevista foi variável (de uma a três horas), ocasionando reencontros apenas quando o entrevistado manifestou interesse, o que sucedeu em três casos. A curta duração deste projecto exploratório, a decisão de filmar as entrevistas, e a idade avançada dos nossos interlocutores (com uma média de 80 anos) ditaram a não realização de encontros múltiplos. Em Junho de 2018, realizei duas novas entrevistas, agora gravadas em suporte áudio. Todas as entrevistas tiveram lugar em Lisboa ou arredores.

7 Designadamente, o Fundo do Cinema Nacional (criado em 1948) e, a partir de 1961, a Fundação Calouste Gulbenkian. 
O que emergiu destas entrevistas foi um retrato complexo das relações entre práticas cinematográficas e turísticas que se estabeleceram no momento da rodagem de alguns filmes. Foi possível, por um lado, verificar que, durante a produção das imagens, foram feitas opções vividas e incarnadas que se revelaram cruciais para o formato final dos filmes, sendo possível falar de um reforço mútuo e harmonizado entre os dois tipos de práticas. A análise do filme Albufeira (1968), do realizador António de Macedo, que desenvolvo na primeira parte deste artigo, ilustra bem esse processo. ${ }^{8}$ As entrevistas trouxeram ainda a lume incompatibilidades de fundo entre os campos turístico e cinematográfico - entendidos nos termos descritos e operacionalizados por Pierre Bourdieu, nomeadamente nos seus escritos sobre o campo literário (1993). A ideia de que pudesse ter havido uma sobreposição (ou um contágio) entre práticas cinematográficas e práticas turísticas durante a produção dos filmes discutidos causou equívocos e desconforto em alguns dos meus interlocutores, que exploro na segunda parte do artigo. Por fim, os relatos que recolhi sugerem um campo cinematográfico caracterizado por uma grande instabilidade, onde os filmes turísticos, juntamente com outros filmes "utilitários ou de utilidade" (Hediger e Vondereau 2009), desempenhavam um papel importante na vida destes profissionais. Este aspecto tem sido desconsiderado na maior parte dos estudos sobre cinema português e merece ser alvo de reavaliação. Disso darei conta na terceira e última parte do artigo.

\section{IMAGENS PRATICADAS: ALBUFEIRA (1968)}

Em 2015, o visionamento, nas instalações do ANIM, de uma cópia do filme Albufeira foi um dos motivos para solicitar uma entrevista a António de Macedo e a Elso Roque, respectivamente, realizador e director de fotografia deste filme. Produzida por Francisco de Castro ${ }^{9}$ para promover turisticamente a região algarvia pouco tempo depois da abertura do aeroporto de Faro (1965), esta curta-metragem de $35 \mathrm{~mm}$, filmada a cores, adopta o tom ligeiro e bem-disposto, então muito em voga num certo tipo de cinema narrativo, para contar as experiências de três raparigas americanas que se encontram de visita a Albufeira para escrever um artigo ilustrado para uma revista americana. É, pois, num formato ficcional, narrado na primeira pessoa e em voz-off por uma das personagens (que, na versão portuguesa, fala com sotaque estrangeiro) e,

8 Procurei manter o anonimato dos meus interlocutores quando discuto aspectos gerais (e tendencialmente especulativos), mas não quando analiso filmes específicos que foram abordados durante as entrevistas. Esta opção algo heterodoxa resultou da necessidade de identificar os filmes, que estão no domínio público e podem ser vistos.

9 Francisco de Castro era um dos nomes mais respeitados do sector documentarista, nesta década e na seguinte. A sua empresa de produção proporcionou trabalho a realizadores como António de Macedo, Fonseca e Costa, António Escudeiro, entre outros. 
portanto, através da mediação das três turistas, que Albufeira nos é dada a descobrir. Apesar de ter envolvido patrocinadores menores, como restaurantes, bares nocturnos e outros comércios locais, o filme foi uma encomenda da Câmara Municipal e da Junta de Turismo que, segundo Macedo, fizeram recomendações sobre os sítios e eventos que desejavam ver no filme. A encomenda pedia que o filme mostrasse os momentos altos da vida de Albufeira ao longo de um ano, a fim de incluir atracções como as amendoeiras em flor (em Fevereiro); os festejos da Páscoa; a celebração do "Dia do Turista" (25 de Abril); a apanha do morango (em Maio) e, naturalmente, a estação balnear, nos meses de Verão. Para além de permitir um retrato mais completo da localidade (que ia ao encontro do tradicional "filme regional", de cariz monográfico, muito do agrado das autoridades locais), a adopção de um ciclo longo visava também contrariar a sazonalidade do sector turístico, ao mostrar o Algarve como uma região de clima ameno também nos meses mais frios. ${ }^{10}$ A estrutura ficcional, que contemplou recursos retóricos como a analepse e a citação de diários e "notas de campo", foi a solução que o realizador encontrou para juntar esta diversidade de eventos, espaços e temporalidades e, desse modo, satisfazer os requisitos da encomenda.

Macedo confirmou que a equipa de rodagem teve que viajar para Albufeira várias vezes; mas também referiu uma estadia mais longa, de duas semanas, durante o Verão, quando ele e o director de fotografia, "pagos pela produção do filme" [entrevista 7, 12/03/2015], alugaram uma casa de férias com as respectivas famílias. Esta ocasião terá permitido à equipa experimentar Albufeira como um destino de férias em primeira mão, o que terá resultado numa representação dos turistas e do turismo mais imersiva e inovadora. Com efeito, longe de serem um pretexto ou uma âncora para a inserção de vistas pitorescas (como acontecia na maior parte dos filmes turísticos dos anos 40 e 50 - cf. Sampaio 2014), as três turistas, modelos de profissão, emergem neste filme como corpos atraentes que interagem fisicamente com o espaço envolvente. Vemo-las a desenvolver práticas tão diferentes como percorrer a região ao volante de um jipe, sair à noite, dançar numa boîte ao som de uma banda yé-yé, comer em restaurantes e esplanadas, visitar o mercado, ir à praia, interagir com a população local, etc. É provável que o próprio Macedo se tenha envolvido em muitas destas práticas durante a sua estadia em Albufeira. O filme oferece-nos momentos de curiosa imbricação de práticas cinematográficas e práticas turísticas:

10 Esta lógica climática aplicava-se também ao resto do país, como sugerem os vários filmes que incluem "Abril" no título (ex.: April in Portugal, realizado por Euan Lloyd, no Reino Unido, em 1956) ou que situam a visita a Portugal nesse mês. Macedo mostrou-se crítico deste aspecto do seu filme: “[...] aquela coisa que havia na altura, 'Abril em Portugal', quer dizer, 'Portugal é um país tão bom turisticamente, que até em Abril...' que noutros países é um mês impossível de frio, e chuva e não sei quê... ‘Abril em Portugal é uma maravilha!' Não é verdade." [Entrevista 1, 02/03/2015] 
as raparigas são frequentemente vistas a fotografar e a filmar com uma câmara amadora os objectos e as paisagens que aparecem no filme. Numa técnica antiga que remonta ao cinema mudo, é inserida uma moldura em alguns destes planos, que visa distinguir entre as imagens subjectivas mediadas pelas câmaras destas turistas e as imagens objectivas (e pretensamente não-mediadas) do próprio filme. As experiências das protagonistas são, deste modo, apresentadas como activas e pessoais, e não gerais e "recebidas". A possibilidade, cada vez mais real, de viajar até Albufeira, abre-se aos espectadores do filme que, com câmaras amadoras suas, poderão vir a querer experimentar as mesmas práticas visuais turísticas.

Macedo mencionou também dois episódios que sugerem a "contaminação" de representações ficcionais por práticas reais incarnadas. O primeiro diz respeito à cena em que uma das raparigas (personificando uma repórter profissional) entrevista, com o seu gravador, um pescador na praia. O realizador descreveu a cena como uma "mentira", já que resultara da montagem de excertos de uma entrevista que ele próprio conduzira:

“[...] aquelas cenas dos pescadores que lá aparecem, aquilo foi gravado mesmo... os pescadores é que responderam àquelas perguntas. As perguntas que lá aparecem, fui eu que as fiz [...] depois fiz uma montagem em que pus a voz da locutora estrangeira a repetir as perguntas que eu tinha feito e a colar com as respostas que eles davam. Portanto, aquilo que vocês vêem no filme é uma aldrabice pegada do princípio ao fim. Aliás, para isso é que serve o cinema, da realidade estamos nós fartos. Portanto aquelas entrevistas que elas fazem, que os pescadores respondem, é tudo mentira, não foi nada assim. Fui eu que fiz as entrevistas aos pescadores, aproveitei das respostas que eles deram só os bocados que me interessavam. Mais ainda: de algumas coisas que eles disseram, eu inventei perguntas para aquilo." [Entrevista 7, 12/03/2015]

Apesar do tom depreciativo, que tem por alvo uma visão idealista do cinema, este episódio coloca em evidência a dedicação e habilidade profissionais do realizador, que lançou mão a um rol de tarefas demoradas e elaboradas (incluindo uma espécie de pesquisa etnográfica sobre os pescadores da localidade), para produzir uma sequência de imagens relativamente breve. O excerto dá voz à criatividade e agencialidade do realizador, que emergem também noutras entrevistas como duas das componentes identitárias mais importantes deste grupo profissional.

O segundo episódio relaciona-se com a rodagem de imagens subaquáticas. Num dos momentos centrais do filme, as três turistas chegam à praia, despem a roupa e mergulham de fato de banho no mar. É então que as vemos a nadar debaixo de água, num registo documental inovador que consegue transmitir, 
de forma imersiva, os aspectos sensoriais mais subtis desta actividade balnear. Segundo o realizador e o director de fotografia, foram as primeiras imagens subaquáticas do cinema português. Em entrevistas separadas, ambos os profissionais descreveram, com algum pormenor, a construção improvisada e artesanal de uma câmara à prova de água a partir de uma panela de pressão, bem como os testes realizados na praia e no laboratório para se obterem os resultados técnicos desejados. A sequência - uns 30 segundos de imagens ao som de uma música jovial - oferece uma representação sinestésica do prazer associado ao banho de mar (e à observação do corpo feminino). Estas e outras imagens do filme são ilustrativas da deslocação, que se fazia sentir em Portugal, de actividades turísticas centradas no ver as vistas (geralmente associadas à visita de monumentos históricos nacionais), para actividades turísticas desenvolvidas em torno da tríade mar-areia-e-sol, onde o corpo do(a) turista e outros sentidos que não a visão assumem algum destaque (Sampaio 2017).

\section{"JÁ LEVÁVAMOS A COISA A SÉRIO": AS PRÁTICAS DO SABER-FAZER}

A tarefa de recuperar, através de entrevistas, as práticas e os contextos de produção das imagens visionadas conheceu algumas dificuldades que merecem ser analisadas por si só, já que lançam luz sobre as questões em estudo. Em primeiro lugar, ficou claro que os filmes em causa estavam consignados ao esquecimento, em resultado do estatuto de menoridade e marginalidade a que grande parte da história e da historiografia do cinema, dominadas por princípios estéticos e autorais, têm vindo a relegar as imagens em movimento de não-ficção, os formatos curtos e os géneros amadores e "de utilidade" (Sampaio, Schefer e Blank 2016). Ou seja, as entrevistas tinham como alvo privilegiado memórias desvalorizadas e "subexpostas" (cf. Ferreira e Almeida 2017), o que nem suscitava o interesse dos potenciais interlocutores nem fazia antever resultados animadores. ${ }^{11} \mathrm{O}$ primeiro desafio consistiu, portanto, em convencer os contactos que tínhamos a falarem sobre filmes considerados - por si e por outros - como filmes menores, com as dificuldades inerentes a um exercício de rememoração que sucede a um período de desinteresse prolongado.

O enfoque colocado nas práticas também se revelou inesperado. Com a excepção de algum episódio mais marcante - tal como a já referida filmagem submarina, relatada a propósito do filme Albufeira - as minhas inquirições sobre práticas cinematográficas recebiam respostas breves, evasivas ou de carácter

l1 Um exemplo disso foi o longo diálogo que mantive ao telefone com um dos meus contactos, que duvidava da pertinência de falarmos sobre filmes que ele próprio desvalorizava. Ao mesmo tempo que tentava convencer-me da irrelevância desses filmes, ia desvelando pequenas histórias que me sugeriam o contrário. A entrevista foi finalmente marcada e realizada, mas sem que o entrevistado abandonasse a sua atitude. Encontrei a mesma reacção noutros contactos, que acabaram por não conduzir a uma entrevista. 
geral. ${ }^{12}$ Tratava-se, afinal, de falar sobre processos de trabalho que convocavam um tipo de saber que os meus interlocutores consideravam rotineiro, banal, indissociável da experiência e, como tal, dificilmente transmissível a terceiros - muito menos a não-praticantes estranhos ao campo profissional. ${ }^{13} \mathrm{~A}$ isto se junta o facto, mais geral, de o cinema ser uma prática por definição presentacional, cuja visibilidade recai sobre um produto final (o filme) que, por norma, exclui o trabalho que lhe deu forma. ${ }^{14}$

Finalmente, ao considerar lado a lado práticas cinematográficas e práticas turísticas, a hipótese de trabalho implicou um esbatimento - ou até a eliminação - das fronteiras entre turismo e cinema, a ponto de tornar possível interpelar cineastas como turistas e turistas como cineastas. ${ }^{15}$ Esta permeabilidade de fronteiras colocou em causa ideias estabelecidas, quer na esfera do senso comum quer no próprio campo cinematográfico, sobre turismo e cinema, gerando mal-entendidos. Vale a pena concretizar. Questionado sobre se a convivência da equipa de rodagem em viagem também era vivida como uma experiência turística, um dos nossos interlocutores respondeu:

"Não! Já levávamos a coisa a sério. Já não era assim à balda, eram pessoas já com responsabilidade, tanto os realizadores, como o director de produção, como os assistentes, como o director de fotografia. Já era completamente diferente, já tínhamos, já sentíamos que íamos fazer qualquer coisa de responsabilidade. Não era chegar lá, e apontar a câmara e saber se estava bem, não é? As coisas não são bem assim... Já falávamos à noite, 'Olha! Amanhã, vamos filmar para tal parte. O que é que fazemos? O que é que não fazemos?...' Já estudávamos a coisa de outra maneira." 16

12 António de Macedo destacou-se nesse exercício de reflexividade, talvez por já ter escrito sobre o assunto (Macedo 2007).

13 Julgo pertinente uma comparação com o que Emília Margarida Marques escreveu sobre os condutores de máquinas da indústria vidreira da Marinha Grande, para quem o processo técnico "não é, nunca, apenas um modelo cognitivo [...] mas sempre, também, uma coisa tangível, incorporada" (Marques 2004: 142).

14 O cinema também se situa num campo social convergente (da cultura e da arte) dominado por teorias de pendor idealista, mais interessadas em analisar os filmes pelos valores, ideias, ideologias e "imaginários" que veiculam do que pelas suas materialidades mais banais (cf. Sampaio 2015).

15 A investigação não incluiu entrevistas a turistas, mas a ideia de que estes também desenvolvem práticas cinematográficas está-lhe subjacente. Desconhecendo pesquisas sobre a produção amadora de imagens em movimento em contextos turísticos, remeto para os estudos já referidos sobre a fotografia turística amadora (ex.: Larsen 2005, 2006), que ajudaram a pensar os meus resultados.

16 O "já" estabelece uma comparação retórica com tempos anteriores, a fim de sublinhar os avanços que, segundo o entrevistado, ocorreram entre os anos 40-60 e os anos 60-70, com a passagem para o que designa como "novo documentarismo português", em oposição a uma forma "velha" e ultrapassada de fazer documentários. 
Ou seja, perante a sugestão de que pudesse ter havido uma sobreposição entre experiências turísticas e de rodagem, este profissional reagiu defensivamente, como se se tratasse de uma crítica ao seu trabalho. Um outro entrevistado confirmou-me que sentia prazer nas viagens que fazia, mas também sublinhou a noção de que "era serviço, trabalho" [entrevista 14, 03/07/2018]. As responsabilidades que assumia enquanto realizador (e, em alguns casos, enquanto produtor) impediam-no de se envolver com outro tipo de actividades - como, por exemplo, participar nas caçadas dos safaris em que a equipa filmava. Era evidente que, para os meus interlocutores, fazer cinema nada tinha que ver com fazer turismo. Para muitos deles, a linha que os separava dos turistas era clara e inultrapassável. Note-se que, para além do seu sentido literal - que remete para a esfera do lazer temporário, por oposição à esfera (permanente e séria) do trabalho - a expressão "fazer turismo" também significa, em português coloquial, "não fazer nada". Por outras palavras, a mera alusão a uma possível sobreposição entre os dois campos podia ser vista (como no caso supracitado) como uma insinuação de desleixo e falta de profissionalismo.

Tentar perceber como é que os realizadores decidiam o que podia (ou devia) e o que não podia (ou não devia) entrar nos filmes revelou-se outra tarefa difícil. E a questão nem se colocou em relação à censura. ${ }^{17} \mathrm{O}$ meu objectivo era identificar os critérios que tinham estado na base da construção da visão especificamente turística que o filme pretendia transmitir. Por outras palavras, o que é que determinara a inclusão, nos filmes, de certos elementos e não de outros, no âmbito da construção dessa visão? Foram identificadas duas origens para este tipo de decisões: em primeiro lugar, os agentes locais (sobretudo as câmaras municipais) e as juntas de propaganda e turismo, geralmente presentes na fase inicial do processo. Macedo referiu que a primeira coisa que fazia quando iniciava um filme era recolher informações junto dos "especialistas da região, que sabiam que partido se podia tirar, o que é que a região poderia oferecer nas variadas áreas culturais, artísticas, científicas, inclusivamente, industriais" [entrevista 7, 12/03/2015]. A segunda origem revelou-se mais vaga: aparentemente, técnicos e realizadores recorriam a um entendimento implícito, mas de difícil definição, sobre o que era e o que não era turístico - uma espécie de senso comum segundo o qual a escolha de um lugar e de uma atracção, e não de outros, aparecia como natural e óbvia. Afinal, como sugeriu um dos meus interlocutores, era impossível ir a Évora e não filmar o templo de Diana.

A adesão a este "senso comum", experimentado como uma espécie de intuição ou como parte de um saber prático de valor inquestionável, parece ter sido mais determinante do que as recomendações das entidades locais, e poderá

17 Os exemplos que recolhi da acção da censura dizem respeito a longas-metragens de ficção. Nos filmes em análise, a interferência dos clientes da encomenda parece ter estado mais presente. A título de exemplo, veja-se o caso do filme A Cidade (1968), de Fonseca e Costa (Sampaio, Mota e Sá 2016). 
explicar porque é que os conflitos entre realizadores, produtores e clientes acabavam por ser relativamente reduzidos. Na base das discordâncias estavam, geralmente, concepções estéticas divergentes, que opunham os cineastas a elementos externos ao campo cinematográfico. Quando perguntei se era claro, para quem filmava, o que podia ser e não ser turístico, Macedo respondeu:

“Não, por vezes não era, tinham que ser eles [os 'especialistas da região'] a chamar a atenção para isso, porque a nossa tendência era ir para o lado estético. Isso é natural, às vezes o lado estético opõe-se ao turístico. Às vezes, no lado estético, aparecem coisas - por exemplo coisas rudes - que são bonitas, que têm um aspecto forte em termos estéticos, mas que são contraproducentes em termos turísticos. São negativas. Como, por exemplo, aspectos das pessoas mais desfavorecidas, que às vezes, esteticamente, aquilo resulta, porque tem força, mas turisticamente pode ser negativo." [Entrevista 7 , $12 / 03 / 2015]$

Um exemplo da tensão que podia existir entre concepções "turísticas" e concepções "estéticas" do cinema emergiu na nossa conversa com o realizador Fonseca e Costa, a propósito do filme E Era o Mar (1966), sobre o Hotel do Mar, em Sesimbra. O filme não agradou ao proprietário do hotel, responsável pela encomenda, precisamente por defraudar as expectativas que tinha em relação ao que devia ser um filme sobre um hotel. Nas palavras do realizador:

"O dono do hotel tinha na cabeça que o que eu ia fazer era um filme descritivo - este hotel tem 400 quartos, os quartos são assim, o pequeno-almoço é às tantas horas, tem um excelente restaurante... e pouco mais. Eu fiz outra coisa: fiz um filme que é muito mais sobre a construção do hotel, sobre a maneira como foi implantado aí, do que um filme promocional, tal como o dono do hotel entendia que ele deveria ser feito. Do ponto de vista dele, ele talvez tivesse razão; do ponto de vista do arquitecto, ele não tinha. Eu coloquei-me do lado do arquitecto." [Entrevista 6, 24/02/2015]

Este é, talvez, um caso especial, já que teve a intervenção de um actor social exterior quer ao campo turístico quer ao campo cinematográfico: o arquitecto do hotel. Foi ele (e não o proprietário do hotel) quem acompanhou o realizador ao local, onde falou sobre a visão pessoal e arquitectónica que guiara a sua obra $^{18}$ - visão essa que Fonseca e Costa, como nos contou, decidiu integrar no filme. 
Na maior parte dos casos referidos, porém, os realizadores não identificaram qualquer tensão ou incompatibilidade de fundo entre, por um lado, as indicações dos clientes - que, pessoalmente ou através de representantes, conduziam a equipa de filmagens aos lugares que queriam ver no filme - e, por outro lado, a criatividade que lhes assistia (e pela qual eram pagos) enquanto realizadores. Questionado se tivera "carta branca" para fazer o filme Albufeira, Macedo respondeu: "Sim, sim, absolutamente, nunca me levantaram quaisquer limitações” [entrevista 7, 12/03/2015]. Fonseca e Costa fez igualmente notar, na sua entrevista [24/02/2015], a liberdade que sempre tivera para fazer os documentários que lhe eram propostos. Por fim, quando perguntei a um outro realizador se as câmaras municipais interferiam na escolha dos sítios de rodagem, a resposta foi no mesmo sentido: "Não, as câmaras não entravam nisso, ninguém entrava nisso, éramos nós. Dava-se talvez uma volta, e pronto, eu depois decidia o que é que era. Era eu que decidia" [entrevista 14, 03/07/2018].

\section{"PARA VIVER": AS AMBIGUIDADES DE UM OFÍCIO}

É importante notar que o cinema conseguiu impor-se socialmente, não pela sua vocação documental (nos seus inícios, ainda sob influência do positivismo do séc. XIX, o cinematógrafo reclamava ligações privilegiadas com a ciência), mas pela sua vocação artística (cf. Costa 2005), cada vez mais definida enquanto narrativa e enquanto expressão subjectiva de um autor (cf. Granja 2007: 378). Os relatos dos meus interlocutores sugerem que o cinema português dos anos 60 constituía, em termos sociológicos, um campo frágil, dotado de uma cultura profissional em construção, que visava afirmar-se (à imagem do que sucedia no resto do mundo) primordialmente como arte, num processo que implicava o distanciamento quer de práticas fílmicas amadoras (de que o filme doméstico ou "de família" é exemplo) quer de práticas fílmicas "úteis", postas ao serviço da propaganda política e da promoção de empresas, indústrias, produtos ou serviços (de que os cinejornais, os filmes industriais e a publicidade são exemplos paradigmáticos).

A produção do filme turístico situa-se no centro destes processos e conflitos. A maior parte dos profissionais entrevistados pareceu tomar como garantida a visão que divide o cinema entre arte e não-arte. De acordo com esta "visão e divisão" (Bourdieu 1998) do cinema, a arte é a bitola pela qual se mede o sucesso dos cineastas, que têm como objectivo último fazer uma longa-metragem de ficção (também chamada "filme de fundo"). A produção de filmes turísticos e de outros documentários utilitários é, pois, geradora de ambiguidades: se, por um lado, ela é considerada uma actividade menor, assente em práticas repetitivas que visam a obtenção de resultados rápidos a baixo custo (i.e., práticas industriais, tidas como pouco criativas), por outro lado, são-lhe também reconhecidas vantagens práticas. 
Para começar, os documentários constituíam uma das portas de entrada no campo cinematográfico, descrito pela maior parte dos meus interlocutores como de acesso "difícil". ${ }^{19}$ Mais importante, porém, estes filmes garantiam a permanência na profissão, oferecendo uma oportunidade de formação contínua e eventual profissionalização. Com efeito, ao contrário dos filmes de ficção, que se produziam numa base irregular e em número restrito (Cunha 2018: 85), os filmes turísticos, industriais e outros géneros utilitários com uma duração média de 10-15 minutos abriam as sessões dos cinemas comerciais, beneficiando por isso de uma procura constante. Com picos de intensa actividade, ${ }^{20}$ a produção destes filmes proporcionava aos técnicos e realizadores $\mathrm{o}$ acesso a equipamento dispendioso, a oportunidade de aprenderem e experimentarem novas técnicas e a inserção numa equipa e numa rede de contactos mais vasta. Tudo isto garantia o desenvolvimento de uma práxis profissional, um certo reconhecimento dentro e fora do meio cinematográfico e - o que não era de somenos importância - a possibilidade de permanecer numa profissão fortemente marcada pela instabilidade laboral.

Ter um documentário distinguido pelo Prémio Aurélio Paz dos Reis (máxima distinção na área do documentário nacional) ou num festival internacional podia significar a admissão directa no sindicato, apesar de este exigir como requisito mínimo a produção de uma longa-metragem. Foi o que sucedeu a um dos realizadores que entrevistei. No entanto, se viesse a constituir o modo de vida permanente e exclusivo de um cineasta, este tipo de ofício podia facilmente ser visto como um sinal de fracasso. Um dos meus interlocutores viu-se confinado a essa actividade depois de uma experiência negativa com a censura. Fazer documentários trouxe-lhe prémios, o reconhecimento dos seus pares e um contrato permanente e bem pago numa das melhores produtoras de documentários da época. O sucesso encorajou a abertura, com outros sócios, de uma produtora própria, que não vingou, e o ingresso na RTP, já depois do 25 de Abril e "depois de um tempo sem ter nada". Quando lhe perguntei como foi parar ao documentário e porque permaneceu nesse sector, desistindo dos filmes de ficção, respondeu-me, depois de uma breve pausa: "Para viver" [entrevista 13, 19/06/2018].

António de Macedo deu voz a algumas destas ambiguidades, ao referir-se a esta produção não apenas como "filmes alimentares", por suprirem a necessidade que tinha de, nas suas palavras, "imprimir celulóide todos os dias para

19 Identifiquei três portas de entrada: os Serviços Cartográficos do Exército, cujo contacto se dava durante a tropa; a actividade cinematográfica amadora; e o interesse de uma produtora, geralmente em resultado de "conhecimentos". Em qualquer caso, o movimento cineclubista aparece sempre como um factor de relevo. Vários profissionais consideraram existir uma relação directa entre o ver filmes e o querer fazer filmes.

20 Macedo sublinhou esse aspecto: "eu nessa altura filmava muito, estava sempre a trabalhar, às vezes os filmes encavalitavam-se uns nos outros" [entrevista 7, 12/03/2015]. 
viver", mas também como "filmes experimentais" [entrevista 7, 12/03/2015], por lhe permitirem testar soluções técnicas e narrativas que eram depois aplicadas nas suas longas-metragens (cf. Macedo 2007). Este último aspecto, como procurei demonstrar, é central ao filme Albufeira, que possibilitou o desenvolvimento e a harmonização de um conjunto de práticas que visavam o reconhecimento profissional não só no campo cinematográfico, onde o que importava era fazer um bom filme, mas também no campo turístico, onde era igualmente importante fazer um filme eficaz, i.e., cumpridor dos objectivos da encomenda (cf. Hediger e Vondereau 2009).

Por fim, as entrevistas revelaram um caso bastante diferente, a propósito da figura do realizador-produtor Miguel Spiguel (1921-1975), pertencente a uma geração mais antiga, que se especializou na produção de filmes turísticos durante o mesmo período, atingindo elevados níveis de produtividade. ${ }^{21}$ Segundo o testemunho da sua sobrinha [entrevista 5, 05/12/2014], Spiguel não encarava a produção de filmes turísticos como uma fonte de frustração, face a um qualquer desejo, explícito ou latente (que, aparentemente, não existia), de fazer filmes de ficção e construir uma carreira cinematográfica de cunho autoral, reconhecida pelos seus pares como arte. O modus operandi deste profissional seguia um modelo de empreendedorismo de base unipessoal que recorria a uma equipa mínima, mais ou menos fixa, apenas quando necessário. Era Spiguel quem directamente se ocupava das diversas fases dos filmes - desde a angariação de subsídios e fundos junto do Estado ou de outros patrocinadores (através de uma intensa actividade epistolar, de que consultei alguns exemplos), até à promoção dos filmes junto de várias entidades, de forma a explorar diferentes oportunidades de colocação daqueles no mercado, passando pela escrita dos guiões, o trabalho de repérage e a rodagem nos locais. Os filmes dependiam da realização de longas viagens - sobretudo às colónias - das quais, segundo a sua sobrinha, o realizador retirava grande prazer e cuja planificação se confundia com a planificação dos próprios filmes. Das entrevistas que realizámos esta foi a única em que a introdução da questão turística em relação à experiência de rodagem não foi motivo de equívocos ou desvalorização, sendo antes encarada como uma parte natural (e bastante apreciada) do próprio processo de rodagem. ${ }^{22}$

\section{CONSIDERAÇÕES FINAIS}

O corpo foi já descrito como "o grande ausente dos estudos turísticos" (Obrador 2008), em resultado do enfoque que as últimas três ou quatro décadas têm

21 Entre 1952 e 1974 é-lhe atribuída a realização de quase 60 filmes, na sua maioria documentários de curta duração.

22 A nossa interlocutora, que também trabalhou como realizadora, revelou um sentido igualmente pragmático em relação à vertente comercial (business) do cinema. 
dado às dimensões visual, semiótica e cultural do turismo, que fez com que este tenha sido estudado sobretudo como um sistema de signos, discursos e representações. Esta ausência estende-se aos estudos de cinema, para os quais o realizador (quando considerado) é um autor, nunca um corpo em laboração. O trabalho que tenho realizado sobre as imagens em movimento turísticas temme confrontado com a necessidade de as compreender também à luz das práticas que lhes deram forma. Tomando a sério o argumento de que o impulso da viagem acompanha o cinema desde as suas origens (Costa 2017: 7), tenho procurado inquirir de que modo é que os dois tipos de práticas (cinematográficas e turísticas) convergiram na produção de imagens turísticas concretas a partir da análise das marcas ou dos traços que essa convergência terá deixado em imagens de arquivo. A tarefa nem é de fácil implementação nem garante resultados conclusivos. A premissa de que essas imagens existem e fazem sentido em relação a um campo cinematográfico não chega, por si só, para evocar a totalidade desse campo, que conseguimos vislumbrar apenas em fragmentos. Um laborioso trabalho de construção de estudos de caso articulados, capaz de ligar níveis de macro-, meso- e micro-análise, permanece, em larga medida, por fazer.

O visionamento de imagens de arquivo e a sua análise à luz de dados recolhidos em entrevistas sugerem que a representação incarnada e imersiva dos turistas e do turístico que vemos surgir nos anos 60 resultou não tanto da imposição de um olhar turístico por parte da indústria ou do Estado (apesar de este factor não poder ser desvalorizado) como da sobreposição e imbricação de experiências cinematográficas e turísticas concretas. Se fazer turismo envolve sempre um corpo que vê, come, viaja, experimenta, fazer cinema envolve sempre um corpo que filma. Por outro lado, talvez por se tratar de uma prática corrente, a encomenda nunca nos foi apresentada como uma imposição à qual os cineastas se tinham de submeter. Na verdade, ela frequentemente surgia por iniciativa das produtoras e não das entidades turísticas ou industriais. A produtora de Francisco de Castro tinha pelo menos um angariador de encomendas, i.e., uma pessoa que viajava pelo país a sondar o interesse que as várias câmaras municipais, juntas de turismo e fábricas podiam ter num filme de promoção. Foi essa a origem do filme Albufeira, definido pelo realizador como "uma encomenda provocada" [entrevista 7, 12/03/2015]. Do mesmo modo - salvo em episódios relatados como excepcionais - nenhum dos nossos interlocutores referiu a existência de constrangimentos à sua actividade. Muito pelo contrário: foram-nos fornecidos vários exemplos de experimentação criativa, e os realizadores não deixaram de sublinhar a total responsabilidade pelas decisões tomadas, mesmo em situações de conflito. Por conseguinte, dificilmente podemos entender a produção destas imagens turísticas como parte de um "círculo hermenêutico" (Haldrup e Larsen 2003; Larsen 2006), onde as mesmas representações são passivamente recebidas (i.e., "consumidas") e reproduzidas, alheias à mediação de agentes incarnados e situados. 
No entanto, também é verdade que os vários interlocutores nos deram conta da existência de um conjunto de noções práticas e estéticas que os guiava na escolha dos motivos de interesse turístico que desejavam trazer para os seus filmes. Ainda que nele ratificado, estas noções ultrapassam o campo turístico, admitindo sobreposições com ideias e práticas políticas dominantes e extravasando para uma espécie de senso comum que as faz parecer óbvias. É neste quadro que devemos compreender as chamadas "obrigações do Tesouro" - um termo que um dos nossos interlocutores usou com ironia para designar a adesão activa, da parte de alguns profissionais (insuspeitos praticantes do regime freelancer), ao modelo de documentário oficial ideologicamente marcado, com vista a dele capitalizarem na venda dos seus filmes turísticos aos organismos públicos.

À medida que a esfera do turístico se autonomizava da esfera do Estado, este processo perdia terreno ou diluía-se, com resultados contraditórios, ainda antes da queda do regime salazarista-marcelista. O robustecimento do campo cinematográfico também contribuía para as contradições, já que, como vimos, as noções estéticas e cinematográficas nem sempre estavam em sintonia com as noções do turístico. A produção de filmes turísticos constitui um ângulo de análise privilegiado sobre esta triangulação de olhares e saberes práticos. O seu estudo é essencial para uma melhor compreensão não apenas destas imagens, mas também da forma como a visualidade turística tem sido abstraída, mobilizada e reificada para avançar e reforçar determinados entendimentos do turístico, em detrimento de outros. 


\section{BIBLIOGRAFIA}

ALMEIDA, Sónia V. de, 2007, "Campanhas de dinamização cultural e acção cívica do MFA: uma etnografia retrospectiva”, Arquivos da Memória, 2 (nova série): 47-65.

ALmeIDA, Sónia V. de, 2009, Camponeses, Cultura e Revolução: Campanhas de Dinamização Cultural e Acção Cívica do MFA (1974-1975). Lisboa, IELT-Colibri.

BOURDIEU, Pierre, 1993, The Field of Cultural Production: Essays on Art and Literature, ed. e introd. de Randall Johnson. Cambridge, Polity.

BOURdieu, Pierre, 1998, Practical Reason. Cambridge, Polity.

COlemAn, Simon, e Mike CRANG, 2002, Tourism: Between Place and Performance. Nova Iorque e Oxford, Berghahn.

COSTA, José Manuel, 2005, "Notas sobre a percepção do cinema como património cultural”, Leituras: Revista da Biblioteca Nacional, 3 (14-15): 59-67.

COSTA, José Manuel, 2017, "Prefácio", em Sofia Sampaio (org.), Viagens, Olhares e Imagens: Portugal 1910-1980. Lisboa, Cinemateca Portuguesa-Museu do Cinema, 7-9.

CROUCH, David, 2002, "Surrounded by place: embodied encounters", em Simon Coleman, e Mike Crang (orgs.), Tourism: Between Place and Performance. Nova Iorque e Oxford, Berghahn, 207-218.

CROUCH, David, e Luke DESFORGES, 2003, “The sensuous in the tourist encounter. Introduction: The power of the body in tourist studies", Tourist Studies, 3 (1): 5-22.

CUNHA, Paulo, 2018, Uma Nova História do Novo Cinema Português. Odivelas, Edições Outro Modo / Le Monde Diplomatique - edição portuguesa.

EDENSOR, Tim, 2000, "Staging tourism: tourists as performers", Annals of Tourism Research, 27 (2): 322-344.

FERREIRA, Sónia, e Sónia V. de ALMEIDA, 2017, "Retrospective ethnography on $20^{\text {th }}$ century Portugal: fieldwork encounters and its complicities", Social Anthropology / Anthropologie Sociale, 25 (2): 206-220.

GRANJA, Paulo, 2007, "Cineclubes e cinefilia: entre a cultura de massas e a cultura de elites”, Estudos do Século XX, 7: 361-384.

HALDRUP, Michael, e Jonas LARSEN, 2003, “The family gaze”, Tourist Studies, 3 (1): 23-46.

HALDRUP, Michael, e Jonas LARSEN, 2006, "Material cultures of tourism", Leisure Studies, 25 (3): 275-289.

HEDIGER, Vinzenz, e Patrick VONDEREAU (orgs.), 2009, Films that Work. Industrial Film and the Productivity of Media. Amesterdão, Amsterdam University Press.

LARSEN, Jonas, 2005, "Families seen sightseeing: performativity of tourist photography", Space and Culture, 8 (4): 416-434.

LARSEN, Jonas, 2006, "Geographies of tourism photography: choreographies and performances", em Jesper Falkheimer e Andre Jansson (orgs.), Geographies of Communication: The Spatial Turn in Media Studies, Gotemburgo, Nordicom, 243-260.

LOBO, Susana, 2012, Arquitectura e Turismo: Planos e Projectos. As Cenografias do Lazer na Costa

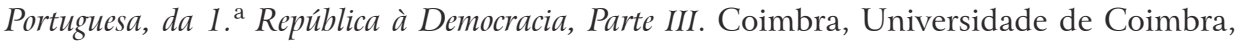
tese de doutoramento.

LORIMER, Hayden, 2005, "Cultural geography: the busyness of being 'more-than-representational”, Progress in Human Geography, 29 (1): 83-94.

MACCANNELl, Dean, 2001, "Tourist agency", Tourist Studies, 1 (1): 23-37. 
MACEDO, António de, 2007, Como se Fazia Cinema em Portugal: Inconfidências de Um Ex-Praticante. Lisboa, Apenas Livros.

MARQUES, Emília Margarida, 2004, "Os operários do fabrico vidreiro automatizado: Máquina, relação e sentido no trabalho industrial”, Etnográfica, 8 (1): 137-149.

MOTA, Gonçalo, 2017, "Modos de ver e mostrar", em Sofia Sampaio (org.), Viagens, Olhares e Imagens: Portugal 1910-1980. Lisboa, Cinemateca Portuguesa-Museu do Cinema, 94-121.

OBRADOR, Pau, 2003, "Being-on-holiday: tourist dwelling, bodies and place", Tourist Studies, 3 (1): 47-66.

OBRADOR, Pau, 2008, “Turismo y cuerpo: un 'tour' por la teoría contemporánea del turismo”, La Ortiga: Revista Cuatrimestral de Arte, Literatura y Pensamiento, 82-83: 123-141 .

SAMPAIO, Sofia, 2013, "Estudar o turismo hoje: para uma revisão crítica dos estudos de turismo”, Etnográfica, 17 (1): 167-182.

SAMPAIO, Sofia, 2014, "O filme turístico em Portugal: 1930-1949", em Paulo Cunha, e Sérgio Dias Branco (orgs.), Atas do III Encontro Anual da AIM. Coimbra, AIM, 416-430.

SAMPAIO, Sofia, 2015, “Turismo, olhares e imagens em movimento: Do arquivo como repositório ao arquivo como campo", Análise Social, L (217): 830-843.

SAMPAIO, Sofia, 2017, “Tourism, gender and consumer culture in late and post-authoritarian Portugal”, Tourist Studies, 17 (2): 200-217.

SAMPAIO, Sofia, 2020, "Confronting the gaze, gripping the virtual: a cultural materialist perspective on cinema-tourism studies”, em Maria Månsson, Anne Buchmann, Cecilia Cassinger, e Lena Eskilsson (orgs.), The Routledge Companion to Media and Tourism, Londres e Nova Iorque, Routledge, 53-60.

SAMPAIO, Sofia, Gonçalo MOTA, e Sérgio Bordalo e SÁ, 2016, "A propósito de duas encomendas: conversa com José Fonseca e Costa", Aniki: Revista Portuguesa da Imagem em Movimento, 3 (1): 121-137.

SAMPAIO, Sofia, Raquel SCHEFER, e Thaís BLANK, 2016, "Filmes utilitários, amadores, órfãos e efémeros: repensando o cinema a partir dos 'outros filmes' ", Aniki: Revista Portuguesa da Imagem em Movimento, 3 (2): 200-213.

THRIfT, Nigel, 2007, Non-Representational Theory: Space, Politics, Affect. Londres e Nova Iorque, Routledge.

URRY, John, 2002 [1990], The Tourist Gaze Second Edition. Londres, Sage.

URRY, John, e Jonas LARSEN, 201 1, The Tourist Gaze 3.0. Londres, Sage.

VEIJOLA, Soile, e Eeva JOKINEN, 1994, “The body in tourism”, Theory Culture \& Society, 11 (3): 125-151. 